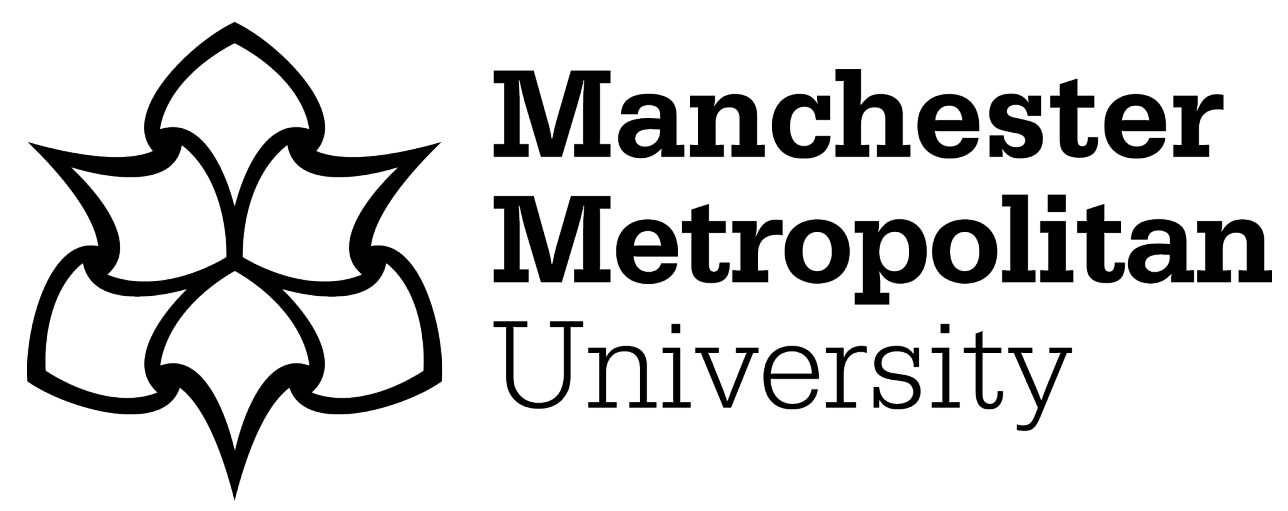

Smith, J, Yeowell, G and Fatoye, F (2017) Clinical and economic evaluation of a Case Management Service for patients with back pain. Journal of Evaluation in Clinical Practice, 23 (6). pp. 1355-1360. ISSN 1356-1294

Downloaded from: https://e-space.mmu.ac.uk/618937/

Version: Accepted Version

Publisher: Wiley

DOI: https://doi.org/10.1111/jep.12797

Please cite the published version 


\title{
Clinical and economic evaluation of a Case Management Service for patients with back pain
}

\author{
Smith, J., Yeowell, G., Fatoye, F. \\ Journal of Evaluation in Clinical Practice (2017) \\ http://dx.doi.org/10.1111/jep.12797
}

\section{Introduction}

Back pain is the most common and costliest musculoskeletal condition in the United Kingdom (UK), affecting $30 \%$ of the adult population annually $[1,2]$. It is associated with functional limitation, depression and anxiety, and thus reduced quality of life (QoL) [3]. In addition, back pain is the leading cause of productivity loss due to absence from work and is associated with significant healthcare resource use [4]. The annual cost of back pain for investigations, treatment, and loss of productivity resulting from disability, has been estimated to be $£ 1.6$ billion. Costs relating to services provided in the private sector account for $35 \%$ of this figure [4].

Due to the considerable personal and economic burden of back pain, new and innovative ways of delivering clinically and cost-effective measures are constantly sought by healthcare providers. In the National Health Service (NHS), Musculoskeletal Clinical Assessment Services (MCAS) have been developed to manage back pain. Here, Advanced Physiotherapy Practitioners triage referrals and manage patients along locally implemented pathways. A number of benefits of this type of service have been reported including: a reduction in unnecessary referrals to secondary care [5,6]; enhanced patient satisfaction [7,8] improved surgical conversion rates [7], and improved patient reported outcomes including generic health status and pain [8]. 
In 2011, over 80000 of the 2.5 million clients of one UK private healthcare provider were treated for back pain. In response to the large number of people requiring assessment and treatment of back pain, a specialised service was required. Thus, the MCAS model was adapted for the private sector and a Case Management Service (CMS), led by physiotherapists, was developed. In contrast to the MCAS service, the CMS was telephone based.

The aim of the CMS was for clients with back pain to receive fast access to advice and the appropriate treatment at the right time. Client assessment was undertaken by a Case Manager using a detailed telephone assessment along with the referring physiotherapist's documentation for the objective assessment. The Case Manager, based within the private insurance provider setting, had an overview of the client's treatment pathway, insurance policy benefits and clinical presentations. Their role was to facilitate early access to consultants, when necessary; reduce unnecessary diagnostics and surgical referrals, as recommended in the Musculoskeletal Services Framework [9]; and reduce over-treatment with non-evidence based practice. It was therefore anticipated that the CMS should improve patient outcomes while potentially decreasing the total overall cost of treatment.

However, CMS is a relatively new area for musculoskeletal physiotherapists to be involved in within the UK. Moreover, the clinical and cost-effectiveness of a physiotherapy led CMS in the UK private sector has not been documented. Due to differences between private and public healthcare sectors in terms of access and service delivery, the NHS based literature may not be transferable to the private 
sector. Therefore, the aim of this study was to evaluate the clinical effectiveness and resource use of a UK private sector, Case Management Service.

\section{Methodology}

\section{Design}

An observational cohort study was undertaken to investigate the aim of this study.

This was based on prospective data collection of patient reported outcome measures (PROMs) and data collection from an existing administrative health database of a UK private healthcare provider. This study is presented in accordance with SQUIRE guidelines [10]. Ethical Approval was obtained for the study from the Manchester Metropolitan University Ethics Committee. Additionally, management approval was obtained from the national provider of private healthcare.

\section{Participants}

Consecutive referrals to the CMS over a three-month period were entered into the evaluation. Participants were identified through their medical records. They were included in the study if they had previously received a minimum of six sessions of therapy and had failed to respond positively to treatment prior to referral to the CMS. The participants were aged over 18 years with no upper age limit. Participants who were not able to communicate in English, or demonstrated difficulties with telephone communication, were excluded from the study. Participants were also excluded from pre and post PROM collection if at initial assessment they required advice only and no ongoing input, however, they were included in the satisfaction survey. 


\section{Outcome measures}

Functional ability was examined using the Patient Specific Functional Scale (PSFS). This has been designed for assessing functional change in patients with musculoskeletal disorders and has been found to be valid and responsive to change in this population $[11,12]$. The PSFS is scored between 0 and 10 for each activity that is limited by the condition for which the client is seeking treatment; 10 being no problems and zero being unable to perform the activity. The overall PSFS score is an average of all activity scores.

QoL was examined, using EQ-5D-5L, a generic PROM, that has been shown to be reliable and valid for musculoskeletal conditions $[3,13]$ and adopted for use by the UK National PROMs programme. Patient perceived improvement was assessed using EQ-VAS which is an integral component of the EQ-5D-5L and is recognised as being clinically relevant when taken alongside PROMs and patient satisfaction $[14,15]$.

The Consultant and Relational Empathy (CARE) measure is a patient reported experience measure (PREM), which examines the patient's experience of the consultation process and is recommended by the Chartered Society of Physiotherapy (CSP) for use in physiotherapy services [13]. It measures empathy in the context of the therapeutic relationship during a one-on-one consultation and can be used to assess client satisfaction [16]. The questionnaire consists of ten questions concerning the performance of the therapist, and is rated on a scale from 1 (poor) to 5 (excellent) with a maximum total score of 50 and a minimum of 10 . A higher score indicates a greater perception of therapist empathy and satisfaction. 
The CARE measure has been found to have face and content validity with high internal reliability and to be stable across different socio-economic patient groups [16].

\section{Cost Consequences analysis}

Cost consequences analysis, a method of economic evaluation with incremental costs reported separately to other outcomes [17]. The analysis was completed using an existing dataset extracted from an administrative database, by selecting all claims data (including cost of: therapies, consultant appointments, investigations and injections) for adults with a primary diagnosis of back or spinal pain over an 11month period from the total lives covered. Data was coded and anonymised for analysis.

\section{Procedure}

At initial assessment the Case Manager completed outcome measures: PSFS and EQ-5D-5L, verbally over the phone as per usual Case Management process. The client was then managed within the service in accordance with usual CMS pathways. At the point at which the client's case was closed, repeat outcome measures: PSFS and EQ-5D-5L were taken and the CARE satisfaction questionnaire was distributed.

\section{Data Analysis}

Descriptive statistics were used to summarise patient demographics. Where data was normally distributed, means and standard deviation (SD) were used; however, median and interquartile range were used for non-normally distributed data. Changes between baseline and follow-up, for all health outcomes data were 
assessed using Wilcoxon Signed Rank test. The significant value set was $p<0.05$. The correlation between PSFS change and chronicity of symptoms was assessed using Spearman rho correlation analysis.

Descriptive analysis was used for cost consequences evaluation. The analysis was used as a description of overall and itemised cost of resource use within back care. The analysis was completed for January to November 2011; pre-CMS implementation, and during the same period, January to November 2014; post-CMS implementation.

\section{Results}

One hundred and ten clients were referred to the study, 62 of whom completed the full set of outcome measures (Figure 1). Of the 62 participants, 43 were female. The mean age of the participants was 45.73 (SD 12.02) and mean chronicity of symptoms was 16.93 months (SD 50.64).

\section{Figure 1 around here}

Following CMS there was a statistically significant improvement in QoL $(p<0.0001)$. There were also significant improvements in perceived improvement score and function (both $p<0.0001$ ), following the CMS (Table 1). There was a weak correlation between chronicity of symptoms at point of referral and PSFS outcome ( $r$ $=0.201 ; p=0.106)$.

\section{Table 1 around here}




\section{Patient Reported Experience Measure}

Ninety-six percent of the sample rated their Case Management experience as between good and excellent showing a high level of satisfaction with the CMS (Figure 2).

\section{Figure 2 around here}

\section{Cost Consequences}

An analysis of the cost consequences data examining the total number of therapy sessions provided for clients between January and November in 2014, two years after CMS implementation, compared to January to November in 2011, prior CMS development are presented in Table 2.

From the total number of clients in $2011,3.12 \%$ of clients received treatment for their back complaint (Table 2). In 2014, whilst the total number of clients had decreased by $13 \%$, the percentage of clients receiving back care increased to $3.65 \%$, indicating an increase of $0.53 \%$ compared to 2011 . Alongside this, the total number of individual therapy sessions delivered in 2014 had reduced by 53,475 compared to 2011 (Table 2). The average number of sessions per client also reduced in 2014 from 6.7 to 4.7 compared to 2011 , a reduction in sessional average of 2 sessions per member. The number of clients attending a consultant appointment for their back care increased from $80 \%$ to $89 \%$ from 2011 to 2014 (Table 3). Referrals for MRI scans also increased from $18 \%$ to $23 \%$. The total lives covered decreased slightly from 2011 to 2014 (Table 3). 
Table 2 and 3 around here

\section{Discussion}

The aim of this study was to evaluate a CMS, in terms of effectiveness on health outcomes and patient satisfaction. It also examined the resource use of the CMS. The key findings were that health outcomes significantly improved following CMS with high levels of participant satisfaction. The CMS was also associated with reduced therapy resource use.

It was found that the health outcomes measured, showed significant improvement in QoL and functional ability following CMS intervention. The minimum clinically important difference (MCID) for the PSFS is considered to be 2 points [18]. The mean change in PSFS post-CMS was 1.98, and therefore is approaching a clinically significant score, in addition to it being statistically significant. These findings contrast, in part, with the findings of Sephton et al [8], who undertook an evaluation of MCAS in Primary Care, which used a similar approach to the CMS approach used in this study. They found that there was a differential response by region treated, with patients with spinal pain showing less improvement in patient outcomes, than patients with upper or lower limb pain. These conflicting findings may be a result of the CMS being developed as a specialist service for back care delivered by spinal specialists, whereas the MCAS was delivered for generic musculoskeletal conditions. It may also be due to the differences in the setting, with the Sephton et al [8] study being carried out in the NHS, compared to this study set within Private Health Care, where the setting and delivery of care may be different. Sample differences may also account for the conflicting findings. Sephton et al's [8] sample 
had only $42 \%$ in employment, whereas the large majority $(70 \%)$ of the private healthcare participants in this study were employed. Not being in employment has been found to have a strong association with a risk of poor prognosis in back pain [19]. Analysis of the relationship between chronicity of symptoms and health outcomes, found no correlation between the duration of symptoms at baseline and improvement in QoL and function, post intervention. This contrasts to other studies who found increased chronicity of symptoms, to be a predictor of poor outcomes [8]. However, this may be related to the chronicity in this study being relatively low (17 months) compared to other studies (45 months) [8].

The CARE measure, found $96 \%$ of clients rated the CMS as good to excellent, thus indicating their satisfaction with the service. The CARE measure score has been found to be predictive of enablement and health changes following consultation across a wide range of chronic conditions [20]. This finding is of particular importance for the CMS where enablement of the client to make lifestyle changes such as exercise and work postures, to look after their back long term, is key to the intervention. The reasons for the high level of satisfaction in the current study is unknown. However, this may relate to CMS being provided at no additional cost to the client within their private health care provision. Further research is needed to investigate this.

Cost consequences analysis was completed to describe the total average costs of treatment for back pain in the year before the CMS commenced and the second year following its implementation. This method sets out the resources used alongside health outcomes, allowing the decision makers to apportion their own value to the 
results. Cost consequences analysis has the benefit of being clear to understand and therefore more likely to influence decision making in practice [21]. This method complimented the collection of PROMs and PREM for the full service evaluation, and should result in a clear overview of the current CMS in terms of costs associated with the intervention.

The analysis found both increases and decreases in different aspects of resource use over the two periods observed, before implementation of the CMS and post implementation. These were most importantly, a reduction in cost on therapy provision, and an increased cost on MRI provision following the implementation of CMS. The observed reduction in sessional average by two sessions per member and overall costs reduction of therapies may be due to the role of the Case Manager. In this role, they had the ability to assess the client at an appropriate time point in their treatment pathway and intervene, when necessary, to potentially assist a quicker return to function, and avoid prolonged treatment. Despite the number of clients with back pain receiving therapy increasing and the average cost per session increasing by $16 \%$, the total cost of therapy for back pain had still reduced from 2011 to 2014 by $£ 252842$ (from $£ 10772875$ to $£ 10520034$ ). The percentage of clients with back pain receiving therapies had increased from $54 \%$ in 2011 to $62 \%$ in 2014 ; this is a positive outcome and an area for service development to align the service with current NICE guidance [22] which suggests that $85 \%$ of back pain is nonspecific low back pain and should be managed conservatively.

It has been found that $30 \%$ of the UK population will suffer from back pain in one year [2]. Of these, $20 \%$ will seek GP advice, which is double the percentage of 
clients in this study seeking treatment for back pain, 3.6\%. This specific client group of private policy holders may account for the differences to the national UK population as previously mentioned. In this study, the number of clients attending a consultant appointment had increased from $80 \%$ in 2011 to $88 \%$ in 2014 and following on from this MRI scans delivered has also increased. The total lives covered decreased slightly from 2011 to 2014, and resource use increased by approximately $£ 2$ million (see table 3 ). This increase can be accounted for by the rising spend on MRI scans almost exactly. Referral for MRI had increased by $3.5 \%$ over the observed period. If the MRI cost is excluded in resources use, then the total overall spend only increased by $£ 28364$ which equates an increase of $0.08 \%$.

There were some limitations to this study. The response rates for the clinical data (56\%) and CARE postal questionnaire (24\%) were low and, may have impacted on the findings of the present study. Future research should give due consideration to participant engagement strategies, such as follow-up telephone and email contact. Additionally, satisfaction questionnaire collection may benefit from an online template to allow a less demanding process for the respondent. This study did not investigate the long-term effectiveness of CMS, therefore, it is recommended that a 12-month follow-up for repeat outcome measures could be undertaken to assess maintenance of this improvement. This evaluation has provided evidence to demonstrate quality in healthcare, including patient satisfaction and improved patient reported outcome measures. Following the successful outcomes of the CMS for back care, consideration should be given to extending this service to other musculoskeletal conditions. 


\section{Conclusion}

The clinical and economic evaluation of a UK private sector CMS, showed the provision to be providing significant improvement in health outcomes in terms of quality of life and function, as well as delivering a service that $96 \%$ of users rated as good to excellent. There was also a reduction in overall therapy resource use in the period after the development of the CMS. This is largely due to the reduction in sessional average per client. These results suggest that this model of managing low back pain is cost-effective and provide economic benefit to insurance providers, and subsequently members via policy subscriptions, as well as providing a clinically effective pathway for back pain.

Ethical Approval: Ethical Approval was obtained for the study from Manchester Metropolitan University Ethics Committee. Additionally, management approval was obtained from the national provider of private healthcare.

Funding: This research did not receive any specific grant from funding agencies in the public, commercial, or not-for-profit sectors.

Conflict of Interest: There are no conflicts of interest

References

1. Palmer KT, Walsh K, Bendall H, Cooper C, Coggon D. Back pain in Britain: comparison of two prevalence surveys at an interval of 10 years. BMJ. 2000;320:1577-8. 
2. Macfarlane GJ, Beasley M, Jones EA, Prescott GJ, Docking R, Keeley P, McBeth J, Jones GT, MUSICIAN Study Team. The prevalence and management of low back pain across adulthood: results from a populationbased cross-sectional study (the MUSICIAN study). Pain. 2012;153:27-32.

3. Picavet, HSJ. Hoeymans N. Health related quality of life in multiple musculoskeletal disease SF36 and EQ5D in the DMC3 study. Ann Rheum Dis. $2004 ; 63: 723-9$.

4. Maniadakisa N, Gray A. The economic burden of back pain in the UK. Pain. 2000;84:95-103.

5. Rymaszewski LA, Sharma S, McGill PE, Murdoch A, Freeman S. A team approach to musculoskeletal disorders. Ann Rev Coll Surg Engl. 2005;87:17480.

6. Maddison P, Jones J, Breslin A, Barton C, Fleur J, Lewis R, McSweeney L, Norgain C, Smith S, Thomas C, Tillson C. Improved access and targeting of musculoskeletal services in north-west Wales: targeting early access to musculoskeletal services (TEAMS) programme. BMJ. 2004;329:1325-7.

7. Pearse EO, Maclean A, Ricketts DM. The extended scope physiotherapist in orthopaedic out-patients - an audit. Ann R Coll Surg Engl. 2006;88:653-5.

8. Sephton R, Hough E, Roberts S, Oldham J. Evaluation of a primary care musculoskeletal clinical assessment service: a preliminary study. Physiotherapy. 2010;96:296-302.

9. Department of Health. The musculoskeletal services framework. A joint responsibility: doing it differently. London: The Department of Health 2006.

10. Ogrinc G, Davies L, Goodman D, Batalden P, Davidoff F, Stevens D. SQUIRE 2.0 (Standards for Quality Improvement Reporting Excellence): revised 
publication guidelines from a detailed consensus process. BMJ Quality and Safety. 2015. DOI: 10.1136/bmjqs-2015-004411.

11. Westaway MD, Stratford PW, Binkley JM. The patient-specific functional scale: validation of its use in persons with neck dysfunction. J Orthop Sports Phys Ther. 1998;27:331-8.

12. Sterling M, Brentnall D. Patient Specific Functional Scale. Aust J Physiother. 2007;53(1):65.

13. Chartered Society of Physiotherapy. Outcome and experience measurement. 2016. http://www.csp.org.uk/professional-union/practice/evidencebase/outcome-experience-measurement (accessed 28.7.16).

14. Kamper SJ, Maher CG, Mackay G. Global rating of change scales: a review of strengths and weaknesses and considerations for design. J Manip Ther. 2009;17:163-70.

15. Dworkin RH, Turk DC, Farrar JT, Haythornthwaite JA, Jensen MP, Katz NP, Kerns RD, Stucki G, Allen RR, Bellamy N, Carr DB, Chandler J, Cowan P, Dionne R, Galer BS, Hertz S, Jadad AR, Kramer LD, Manning DC, Martin S, McCormick CG, McDermott MP, McGrath P, Quessy S, Rappaport BA, Robbins W, Robinson JP, Rothman M, Royal MA, Simon L, Stauffer JW, Stein W, Tollett J, Wernicke J, Witter J. Core Outcome measures for chronic pain clinical trials: IMMPACT recommendations. Pain. 2005;113:9-19.

16. Mercer SW, Watt GCM, Maxwell M, Heaney DH. The consultation and relational empathy (CARE) measure: development and preliminary validation and reliability of an empathy-based consultation process measure. Fam Pract. 2004;21:699-705. 
17. Drummond MF, Sculpher MJ, Claxton K, Stoddart GL, Torrance GW. Methods for the economic evaluation of health care programmes. Oxford: Oxford University Press; 2015.

18. Horn K, Jennings S, Richardson G, Vliet D V, Hefford C, Abbott J H. The patient-specific functional scale: psychometrics, clinimetrics, and application as a clinical outcome measure. JOSPT. 2012;42(1):30-42.

19. Vavken P, Ganal-Antono AKB, Quidde J, Shen F, Chapman J, Samartzis D. Fundamentals of clinical outcome assessment for spinal disorders: clinical outcome instruments and applications. Global Spine J. 2015;5:329-338.

20. Mercer SW, Jani BD, Maxwell M, Wong SYS, Watt GCM. Patient enablement requires physician empathy: a cross sectional study of general practice consultations in areas of high and low socioeconomic deprivation in Scotland. BMC Fam Pract. 2012;13:6.

21. Coast J. Is economic evaluation in touch with society's health values? BMJ. $2004 ; 329(7476): 1233-1236$.

22. National Institute for Health and Care Excellence. NICE guidelines (CG88). Low back pain in adults: early management. Manchester: NICE 2009. 
Table 1. Outcome measure analysis

\begin{tabular}{llllll}
\hline Outcome & \multicolumn{2}{l}{ Pre-intervention } & \multicolumn{2}{l}{ Post-intervention } & \\
& Median & IQR & Median & IQR & p-value \\
& & & & & \\
\hline $\begin{array}{l}\text { EQ-5D-5L (QoL) } \\
\text { (max 1.00) }\end{array}$ & 0.6476 & 0.21 & 0.7357 & 0.15 & $<0.0001$ \\
& & & & & \\
$\begin{array}{l}\text { EQ-VAS } \% \\
\text { (perceived } \\
\text { improvement) } \\
\text { (max 100\%) }\end{array}$ & 60 & 20 & 75 & 21.25 & $<0.0001$ \\
$\begin{array}{l}\text { PSFS (Function) } \\
\text { (max 10) }\end{array}$ & 5 & & & & \\
& & & & & \\
\end{tabular}


Table 2. Cost for provision of Therapies

\begin{tabular}{|c|c|c|c|}
\hline & 2011 & 2014 & variation \\
\hline $\begin{array}{l}\text { Average lives } \\
\text { covered (Jan-Nov) }\end{array}$ & 2572874 & 2233945 & $-338929(-13 \%)$ \\
\hline $\begin{array}{l}\text { Individuals } \\
\text { receiving back care } \\
\text { (\%) }\end{array}$ & 80225 (3.12\%) & 81677 (3.65\%) & $+1452(+0.53 \%)$ \\
\hline $\begin{array}{l}\text { Total individuals } \\
\text { receiving therapy } \\
\text { as part of their } \\
\text { back care }\end{array}$ & 44074 (54.93\%) & 51038 (62.49\%) & + $6964(+7.56 \%)$ \\
\hline $\begin{array}{l}\text { Total number of } \\
\text { therapy sessions } \\
\text { provided }\end{array}$ & 295779 & 242304 & -53475 \\
\hline $\begin{array}{l}\text { Average sessions } \\
\text { per member }\end{array}$ & 6.7 & 4.7 & -2.0 \\
\hline $\begin{array}{l}\text { Average cost per } \\
\text { session }\end{array}$ & $£ 36.42$ & $£ 43.42$ & $+£ 6.99$ \\
\hline $\begin{array}{l}\text { Cost per individual } \\
\text { receiving therapies }\end{array}$ & f244.43 & £206.12 & - £38.31 \\
\hline $\begin{array}{l}\text { Total cost of } \\
\text { therapies }\end{array}$ & f10 772875 & f10 520034 & $-£ 252841$ \\
\hline
\end{tabular}


Table 3. Cost for consultations and MRI

\begin{tabular}{|c|c|c|c|}
\hline & 2011 & 2014 & Variation \\
\hline Total lives covered & 2572874 & 2233945 & -338929 \\
\hline $\begin{array}{l}\text { Individuals } \\
\text { receiving back care } \\
\text { from total lives } \\
\text { covered. }\end{array}$ & 80225 (3.11\%) & 81667 (3.66\%) & $+1452(+0.5 \%)$ \\
\hline $\begin{array}{l}\text { Total individuals } \\
\text { receiving a } \\
\text { Consultant } \\
\text { appointment as } \\
\text { part of their back } \\
\text { care }\end{array}$ & $64521(80 \%)$ & 72472 (89\%) & + 7951(+9\%) \\
\hline $\begin{array}{l}\text { Cost per individual } \\
\text { receiving } \\
\text { Consultant } \\
\text { appointment }\end{array}$ & $£ 161$ & $f 162$ & $+£ 1$ \\
\hline $\begin{array}{l}\text { Total cost of } \\
\text { Consultant } \\
\text { appointments }\end{array}$ & f10 390319 & f11 745723 & $+f 1355404$ \\
\hline $\begin{array}{l}\text { Total individuals } \\
\text { investigated with } \\
\text { MRI }\end{array}$ & $14637(18 \%)$ & $19037(23 \%)$ & $+4400(+5 \%)$ \\
\hline $\begin{array}{l}\text { Cost per individual } \\
\text { investigated with } \\
\text { MRI }\end{array}$ & f469.81 & $£ 473.54$ & $+£ 3.70$ \\
\hline Total cost of MRI & f6 876704 & f9 014798 & + £2 138094 \\
\hline $\begin{array}{l}\text { Individuals } \\
\text { receiving spinal } \\
\text { injections as part } \\
\text { of their back care }\end{array}$ & $12276(15 \%)$ & $16996(21 \%)$ & $+4720(+6 \%)$ \\
\hline $\begin{array}{l}\text { Cost per individual } \\
\text { receiving Spinal } \\
\text { injections }\end{array}$ & $£ 377.62$ & $£ 206.21$ & $-£ 171.41$ \\
\hline $\begin{array}{l}\text { Total cost of Spinal } \\
\text { injections }\end{array}$ & f4 635654 & £3 504727 & - f1 130927 \\
\hline $\begin{array}{l}\text { Total overall cost } \\
\text { of Back care }\end{array}$ & f 96738398 & f 102802486 & f 2109759.58 \\
\hline
\end{tabular}




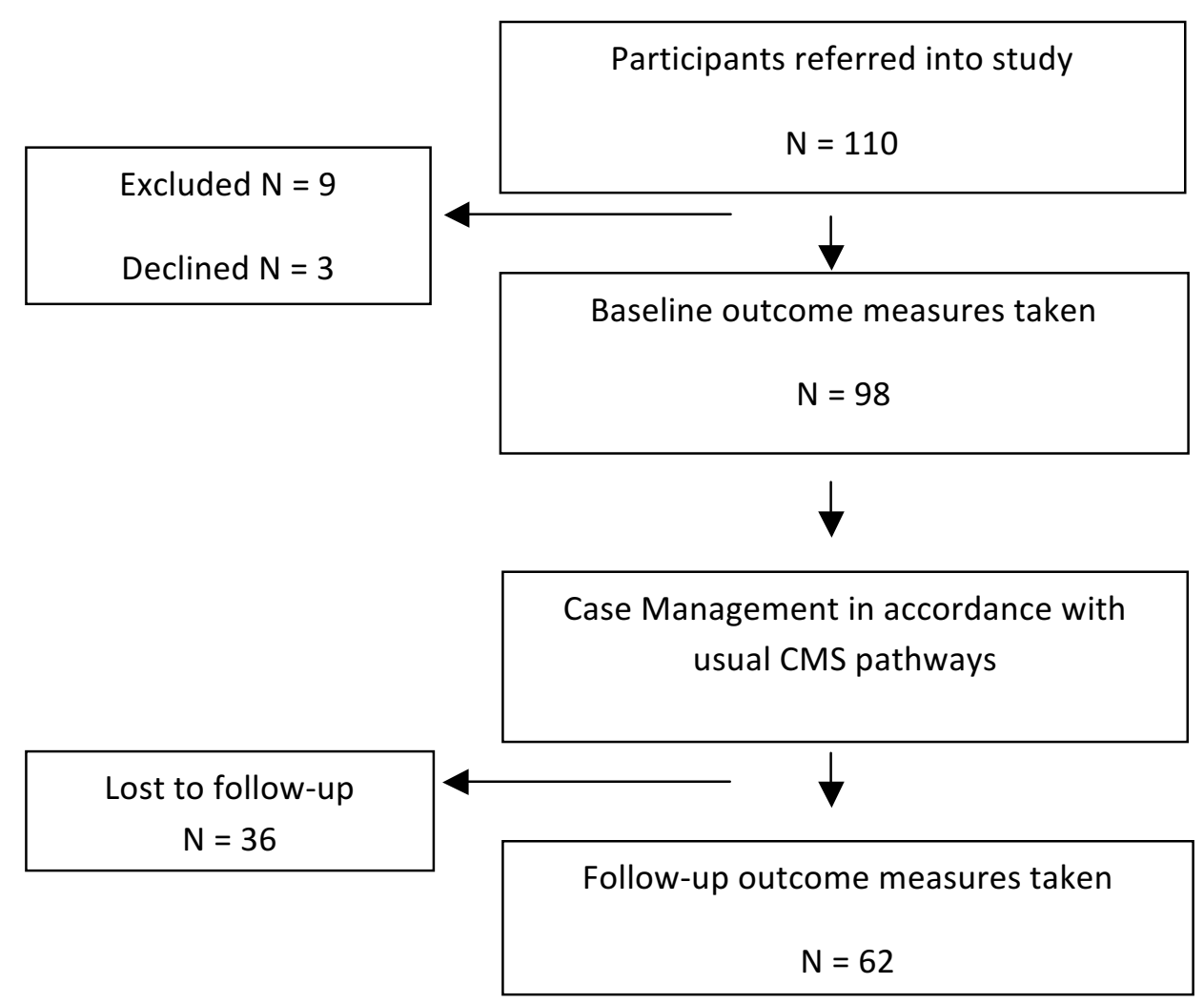

Figure 1. Recruitment and progress through study 


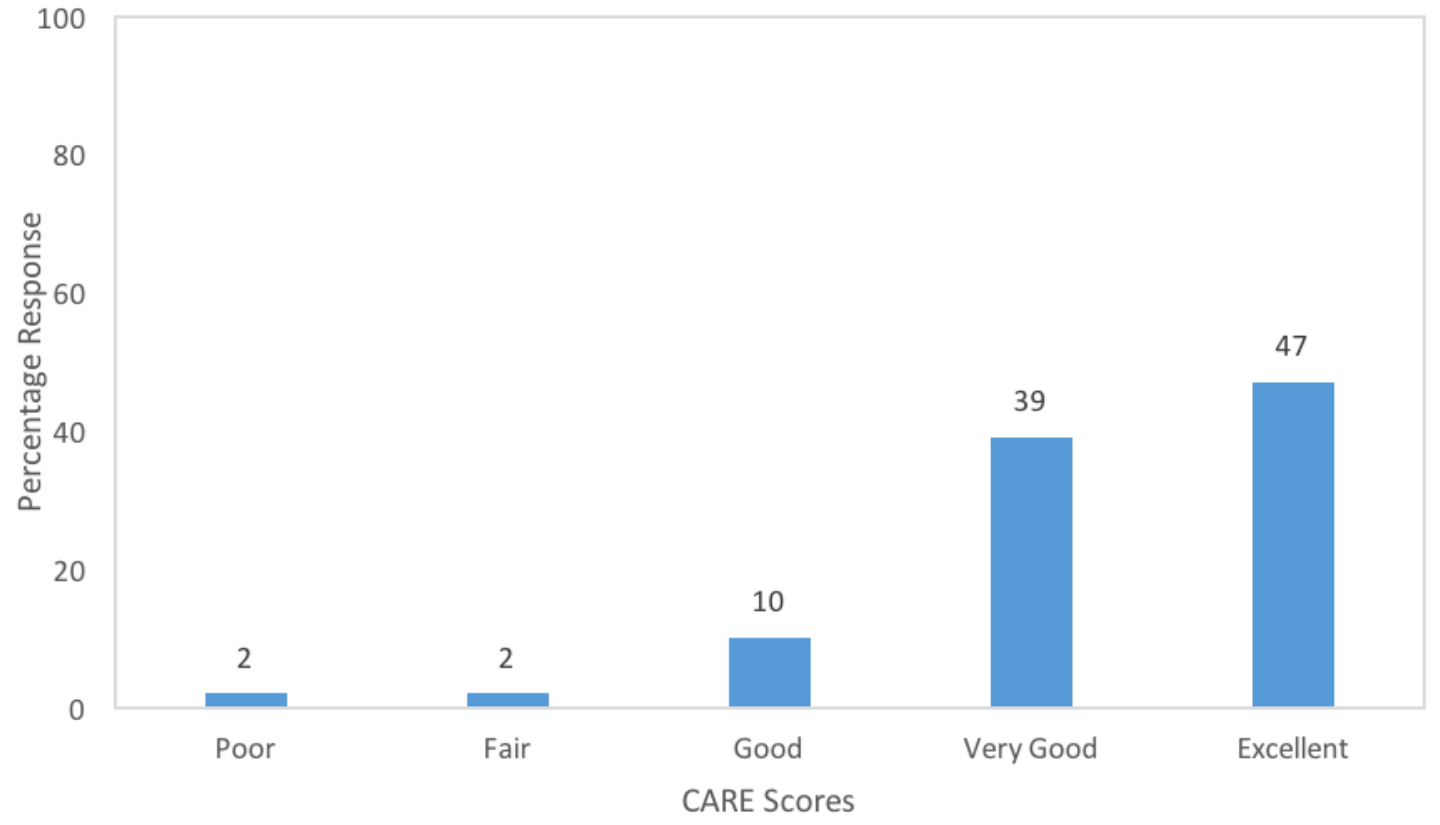

Figure 2. CARE Measure scores following CMS intervention 